\title{
Contamination Status of Hexachlorobenzene (HCB) in Sandstorm Depositions from Beijing and the Origination Region
}

\author{
S. Fu $\cdot$ K. Li $\cdot$ Z. Yang $\cdot$ X. B. Xu
}

Received: 5 October 2007/ Accepted: 17 April 2008/Published online: 9 May 2008

(C) Springer Science+Business Media, LLC 2008

\begin{abstract}
In China, sandstorms play an important role in the long-range atmospheric transport and deposition of hexachlorobenzene (HCB). Concentrations of $\mathrm{HCB}$ in sandstorm depositions sampled from Beijing and the origination region were measured to reveal HCB levels during atmospheric transport. The results suggested a constant level of HCB during atmospheric transport. The values were close to environmental background values indicating that no potential source of HCB existed along the transport route. A tendency for HCB levels in Beijing to increase from north to east was also observed, which was probably due to the influence of wind speed and industrial zone distribution.
\end{abstract}

Keywords Contamination - Deposition ·

Hexachlorobenzene $\cdot$ Sandstorm

Hexachlorobenzene (HCB) has been observed worldwide in air, water, and biota (D'Have et al. 2007). The physicalchemical properties of HCB such as semi-volatility, high stability, and hydrophobicity are favorable for its longrange transport and widespread distribution in nature. Due to bioaccumulation and persistence of $\mathrm{HCB}$, as well as its potential toxicity, international organizations have introduced regulations to reduce or ban the use of HCB (Bailey 2001). Further information on the contamination status of

S. Fu $\cdot$ K. Li $\cdot$ Z. Yang $\cdot$ X. B. Xu $(\bowtie)$

State Key Laboratory of Environmental Chemistry and Ecotoxicology, Research Center for Eco-Environmental Sciences, Chinese Academy of Sciences, P.O. Box 2871, 18 Shuangqing Road, Haidian District, Beijing 100085, People's Republic of China

e-mail: xuxb@rcees.ac.cn
HCB in the environment is still needed by legislators and scientists to identify the contribution of diffusive sources, and to better understand the environmental behavior and source-sink relationships of persistent organic pollutants (POPs).

Long-range atmospheric transport and deposition of pollutants are important aspects of the regional and global transport of these pollutants and of their impact on ecosystems. Of the studies which have focused on the atmospheric occurrence and long-range movement of pollutants such as $\mathrm{HCB}$, only a few have investigated the transport of these pollutants by sandstorms (Weiss et al. 2000). Sandstorms can carry a great many particles and take place irregularly in northern China. For example, northern China experienced eleven sandstorms in 2006, and one storm covered approximately one-eighth of China and deposited about 330,000 tons of sand in Beijing (Han et al. 2007). This event motivated our research into whether sandstorms play an important role in the diffusion of POPs during long-range atmospheric transport and deposition.

Northeast China is one of the areas most affected by sandstorms. Beijing is located in northeast China and is one of the most densely populated cities in the world, with more than 15 million residents. Sandstorms have seriously contaminated Beijing's atmosphere and have had a direct influence on public health. Some of the particles transported by sandstorms can enter the human body via ingestion, inhalation, and dermal routes (D'Have et al. 2007). HCB is a ubiquitous environmental pollutant (D'Have et al. 2007), and carries a high probability of exposure. Nevertheless, few studies have been conducted on the contamination of sandstorm particles and the pollution status has not been well characterized. POPs especially those with environmental persistence such as $\mathrm{HCB}$, can easily accumulate on particles, and eventually 
result in direct or indirect human exposure to these pollutants.

The present study was conducted as a preliminary investigation into the HCB contamination status of sand/dust deposited during a sandstorm and was carried out in order to evaluate the potential risk to human health and to assess ecoenvironmental safety. This approach was designed to provide information on the extent of HCB contamination in the deposited sandstorm particles in Beijing and in the region of Baotou, where the sandstorm originated, and to determine the spatial distribution of the particles, to identify the possible sources of pollution and to investigate possible factors affecting HCB contamination.

\section{Materials and Methods}

A serious sandstorm which developed from the Mongolian cyclone blew over Beijing on April 16, 2006 (Han et al. 2007). Samples of deposited particles were taken in Beijing and Baotou, which are about $600 \mathrm{~km}$ apart (Fig. 1). The first sampling region consisted of 10 urban sites in Beijing covering an area of $750 \mathrm{~km}^{2}$. The climate, at the time, was dominated by temperate, semi-humid monsoon conditions, with daily temperatures ranging from 10 to $27^{\circ} \mathrm{C}$. The second sampling region consisted of three sites in Baotou, Inner Mongolia. Baotou city was chosen as it was in the sandstorm's origination area. The climate in Baotou city was dominated by semi-arid, temperate, continental monsoon conditions, with daily temperatures ranging from 4 to $6^{\circ} \mathrm{C}$. The spring season in Baotou is characterized by strong winds and dry weather. The deposition samples from both regions were ground, sieved through a 60 mesh, then transferred to pre-cleaned amber glass bottles and stored at $4^{\circ} \mathrm{C}$ until analysis.

A HCB standard solution $\left(100 \mu \mathrm{g} \mathrm{mL}^{-1}\right)$ was purchased from the National Research Center for Certified Reference
Materials of China. 2,4,5,6-Tetrachloro- $m$-xylene was purchased from Supelco (Bellefonte, PA, USA). The standards were further diluted to the desired concentration with isooctane and used as working standards. Florisil (60-100 mesh) was purchased from Supelco (Bellefonte, PA, USA) and was activated in a drying oven at $130^{\circ} \mathrm{C}$ for $16 \mathrm{~h}$. Anhydrous sodium sulfate (Beijing Chemical Factory, China) was heated at $600^{\circ} \mathrm{C}$ for $12 \mathrm{~h}$ to destroy organic contaminants before use. All solvents used were of pesticide grade (J. T. Baker, USA).

Five grams of each sample were weighed accurately and ground with anhydrous sodium sulfate into a free-flowing powder. The samples were extracted with $30 \mathrm{~mL}$ of hexane/acetone $(1: 1, \mathrm{v} / \mathrm{v})$ by ultrasound for $4 \mathrm{~min}$, and the extracts were then separated by centrifugation. This process was repeated three times. Before extraction, 2,4,5,6tetrachloro- $m$-xylene was added as a surrogate standard. The extracts were cleaned using a chromatography column (30 $\mathrm{cm} \times 10 \mathrm{~mm}$ i.d.) containing $4 \mathrm{~g}$ of activated florisil with $2 \mathrm{~g}$ anhydrous sodium sulfate. The column was preeluted with $40 \mathrm{~mL}$ hexane/diethyl ether $(4: 1, \mathrm{v} / \mathrm{v})$ before loading the sample. The first fraction containing HCB was eluted using $60 \mathrm{~mL}$ hexane/diethyl ether $(4: 1, \mathrm{v} / \mathrm{v})$. The solvent was evaporated to $100 \mu \mathrm{L}$ in K.D. concentrator under a gentle $\mathrm{N}_{2}$ stream.

Analysis of HCB was carried out using an Agilent 6890 gas chromatograph equipped with a micro-cell ${ }^{63} \mathrm{Ni}$ electron capture detector $(\mu$-ECD). Separation was performed on a $30 \mathrm{~m}$ DB-5MS $(30 \mathrm{~m} \times 0.25 \mathrm{~mm}$ i.d., $0.25 \mu \mathrm{m}$ film thickness) capillary column. The temperature of the injector and detector were $230^{\circ} \mathrm{C}$ and $305^{\circ} \mathrm{C}$, respectively. The GC column was maintained at $100^{\circ} \mathrm{C}$ for $2 \mathrm{~min}$, then ramped at $10^{\circ} \mathrm{C} \mathrm{min}^{-1}$ to $160^{\circ} \mathrm{C}$, further ramped at $4^{\circ} \mathrm{C} \mathrm{min}^{-1}$ to $230^{\circ} \mathrm{C}$, and finally ramped at $10^{\circ} \mathrm{C} \mathrm{min}^{-1}$ to $280^{\circ} \mathrm{C}$ and held at this temperature for $10 \mathrm{~min}$. The total run time was $40.5 \mathrm{~min}$. Quantification of the samples was performed using an external standard.
Fig. 1 Sampling sites of sandstorm deposition: (A) Sampling sites in Baotou and Beijing; (B) Detailed sampling sites in the urban area of Beijing

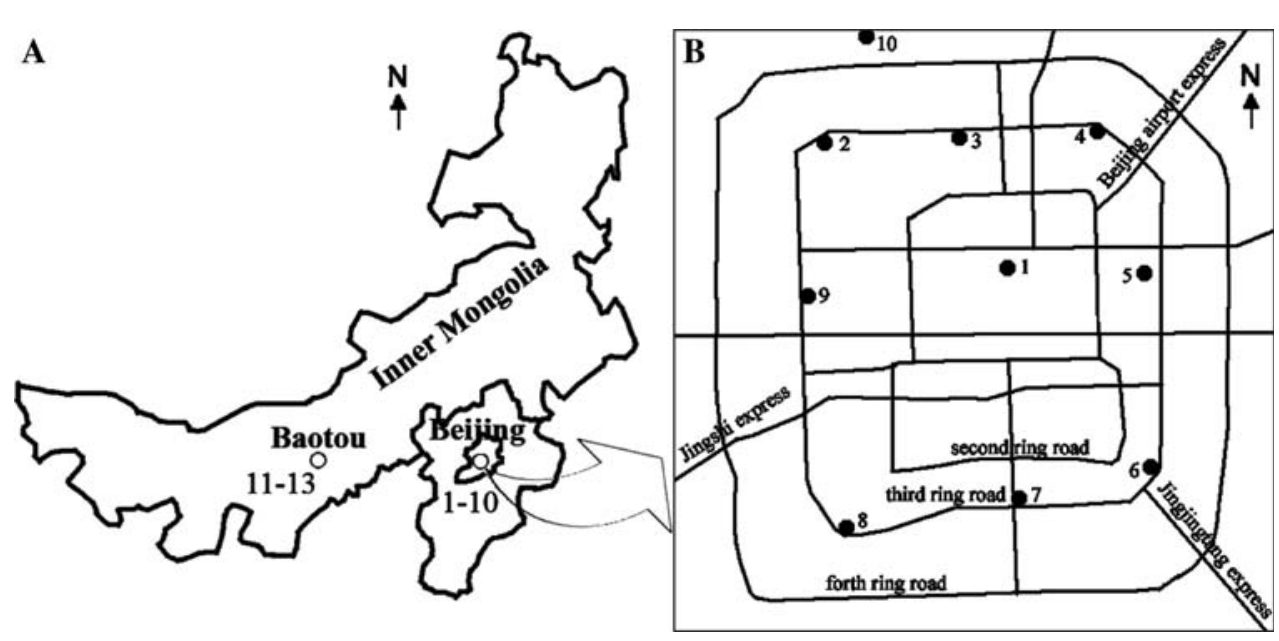


A laboratory blank was run to demonstrate freedom from interference and cross-contamination. In addition, a procedural blank was run in parallel for every set of six samples to check for interference and cross-contamination. The duplicate samples were analyzed in the laboratory along with regular samples, as another quality control tool to ensure the validity of the results. Instrument stability and relative response factor variance were measured by the analysis of calibration standard solutions during each sample batch.

Identification of HCB was confirmed, and concentrations were measured using an external quantification standard consisting of known amounts of the target compound. Two quality control criteria were used to ensure correct identification of the target compound: (a) The GC retention times matched those of the standard compounds within $\pm 0.05 \mathrm{~min}$. (b) The signal-to-noise ratio was greater than 3:1. The limit of detection (LOD) for HCB was defined by a signal-to-noise ratio greater than three times the average baseline variation. The residue concentrations in samples below detection limits were regarded as zero in the calculations of the sum and mean. The LOD for HCB was $0.6 \mathrm{ng} \mathrm{g}^{-1}$. The matrix spike recovery of $\mathrm{HCB}$ was $85 \%$. The recovery of the $2,4,5,6$-tetrachloro- $m$-xylene surrogate in all samples was in the range $70-90 \%$.

\section{Results and Discussion}

HCB was detected in all sandstorm deposition samples. HCB concentrations ranged from 1.1 to $14.6 \mathrm{ng} \mathrm{g}^{-1}$ (median: $4.4 \mathrm{ng} \mathrm{g}^{-1}$, dry weight) in Beijing and 1.1$9.5 \mathrm{ng} \mathrm{g}^{-1}$ (median: $5.3 \mathrm{ng} \mathrm{g}^{-1}$, dry weight) in Baotou (Fig. 2). The median concentrations of HCB in Beijing and in Baotou were similar, indicating a small difference in $\mathrm{HCB}$ concentrations during atmospheric transport. A general increase in HCB concentrations from north to east was also observed in the urban area of Beijing (Fig. 2B).

HCB was widely used in many countries as a cheap, broadspectrum insecticide. Due to its widespread use, HCB has caused significant pollution in China (Wu et al. 1997). The best estimate of global HCB emissions from various sources are as follows: pesticide application $-6,500 \mathrm{~kg}$ year ${ }^{-1}$, manufacturing $-9,500 \mathrm{~kg} \mathrm{year}^{-1}$, and combustion $-7,000 \mathrm{~kg} \mathrm{year}^{-1}$ including $500 \mathrm{~kg}$ from biomass burning. This adds up to a total HCB emission of approximately $23,000 \mathrm{~kg} \mathrm{year}^{-1}$, with an estimated range of 12,000$92,000 \mathrm{~kg} \mathrm{year}^{-1}$ (Bailey 2001). Although the use of HCB as a herbicide has been prohibited, wastes derived from chlorinerelated industries and combustion may be other possible sources of environmental HCB (Meijer et al. 2001).

The physical-chemical properties of HCB, such as vapor pressure $-0.0023 \mathrm{~Pa}$, Kow $-2.6 \times 10^{6}$, Koc $-1.2 \times 10^{-6}$
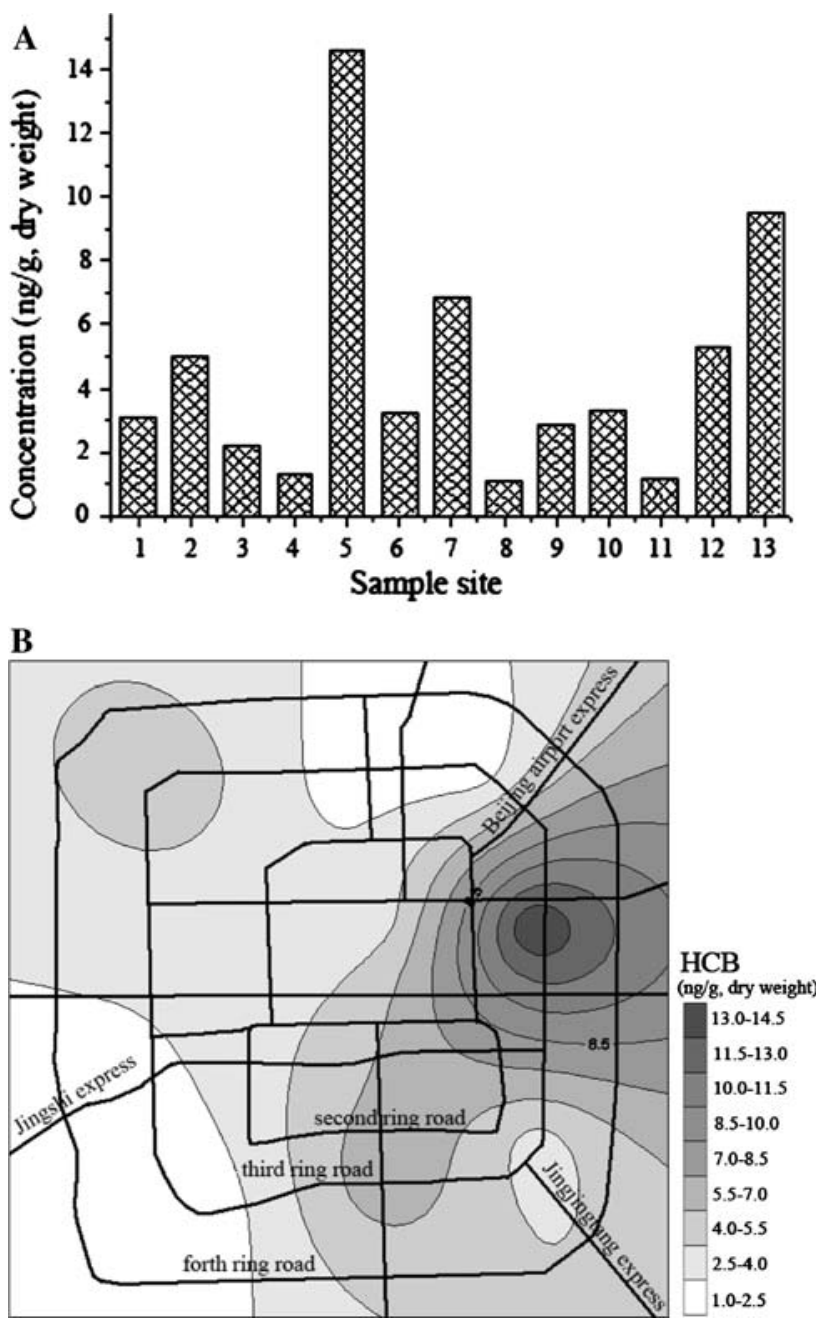

Fig. 2 HCB contamination status: (A) HCB in samples; (B) Contamination status of $\mathrm{HCB}$ in the urban area of Beijing

and $\mathrm{BCF}-2.5 \times 10^{6}$ are favorable for its long-range transport (Mackay et al. 1999). Beyer and other researchers have used the TaPL3 model (transport and persistent level III) to estimate the distance of HCB transport, and have calculated that the transport distance could reach $110,000 \mathrm{~km}$ in air (Beyer et al. 2000). Ockenden studied the worldwide distribution of $\mathrm{HCB}$, and concluded that a high level of contamination occurred between north latitude $30^{\circ}$ and $60^{\circ}$ where the concentrations ranged from ND (not detected) to $5.1 \mathrm{ng} \mathrm{g}^{-1}$ dry weight (Ockenden et al. 1999). HCB concentrations were also found to be approximately $5.5 \mathrm{ng} / \mathrm{g}$ in soil in Belgium, Italy, Greece, and Romania (Covaci et al. 2002). The median HCB concentrations in the present study were similar to the levels found in these European countries which are located within north latitude $30^{\circ}-60^{\circ}$, and close to that found in sediments from Shanghai, China (Nakata et al. 2005).

From the above observations, it can be concluded that the contamination status of $\mathrm{HCB}$ in sandstorm deposits 
from Baotou and Beijing were similar, and the contamination values observed were close to background environmental values. These findings indicate that a potential source of HCB does not exist between Baotou and Beijing. This may be attributed to the banned use of HCB and the rigid regulations relating to $\mathrm{HCB}$ which have been in place for nearly 30 years.

Another interesting finding from the present study, concerned the higher concentration of $\mathrm{HCB}$ found at site 5 in east Beijing (14.6 $\mathrm{ng} \mathrm{g}^{-1}$ dry weight, Fig. 2B). A trend in increased PCB concentrations from north to east was also observed in this study. In Beijing an increasing HCB concentration gradient from site 3 in the north to site 5 in the east was observed, with HCB levels from 2.2 to 14.6 (ng g ${ }^{-1}$ dry weight). A decreasing concentration gradient from site 2 in the north to site 8 in the south from 5.0 to 1.1 (ng/g dry weight) was also identified. Possible reasons for these findings are outlined below:

The contamination status of HCB in Beijing was possibly affected by wind speed. The sandstorm developed from a Mongolian cyclone on April 16, 2006 (Han et al. 2007). Wind-blown sand and floating dust extended to Beijing from northwest to southeast, and the wind speed was noted to be gentle. The huge sandstorm deposits amounted to approximately $20 \mathrm{~g} / \mathrm{m}^{2}$ spread over an area of almost $304,000 \mathrm{~km}^{2}$ (Han et al. 2007). As HCB is a ubiquitous environmental pollutant, it could have been absorbed by airborne particles, transported slowly, and deposited in east Beijing resulting in a higher concentration in this area. Another reason which may explain the contamination status of HCB in Beijing may be the location of the industrial zone which is mainly in east Beijing. The HCB contamination status of the industrial zone was probably higher than that of any other site in the city. These reasons may explain the increased contamination status of $\mathrm{HCB}$ from north to east in the urban area of Beijing.

Acknowledgment This study was supported by the National Natural Scientific Foundation of China (no. 20707031 and no. 20437020).

\section{References}

Bailey RE (2001) Global hexachlorobenzene emissions. Chemosphere 43:167-182. doi:10.1016/S0045-6535(00)00186-7

Beyer A, Mackay D, Matthies M, Wania F, Webster E (2000) Assessing long-range transport potential of persistent organic pollutants. Environ Sci Technol 34:699-703. doi:10.1021/es990207w

Covaci A, Manirakiza P, Schepens P (2002) Persistent organochlorine pollutants in soils from Belgium, Italy, Greece, and Romania. Bull Environ Contam Toxicol 68:97-103. doi:10.1007/s00128-0010224-6

D'Have H, Scheirs J, Covaci A, van den Brink NW, Verhagen R, De Coen W (2007) Non-destructive pollution exposure assessment in the European hedgehog (Erinaceus europaeus): IV. Hair versus soil analysis in exposure and risk assessment of organochlorine compounds. Environ Pollut 145:861-868. doi:10.1016/j. envpol.2006.05.013

Han T, Lin J, Wang Y, Zheng B, Song H, Liu J, Jiang G, Shi P, Zhang J (2007) Nature and control of "dust storms" in the BeijingTianjin region, China - a case study of the dust storm in Beijing on April 16, 2006. Bull Geol 26:117-127 (in Chinese)

Mackay D, Shiu WY, Ma KC (1999) Physical-chemical properties and environmental fate and degradation handbook. Chapman \& Hall, CRCnet Base, CRC Press LLC, Boca Raton, FL 1999 (CD-ROM)

Meijer SN, Halsall CJ, Ockenden WA, Johnston AE, Jones KC (2001) Organochlorine pesticide residues in archived UK soil. Environ Sci Technol 35:1989-1995. doi:10.1021/es0000955

Nakata H, Hirakawa Y, Kawazoe M, Nakabo T, Arizono K, Abe S-I, Kitano T, Shimada H, Watanabe I, Li W, Ding X (2005) Concentrations and compositions of organochlorine contaminants in sediments, soils, crustaceans, fishes and birds collected from Lake Tai, Hangzhou Bay, and Shanghai city region, China. Environ Pollut 133:415-429. doi:10.1016/j.envpol.2004.07.003

Ockenden WA, Meijer SN, Jones KC (1999) Organochlorine contaminants in soils collected from remote sites around the world. Organohalogen Compd 41:321-324

Weiss P, Lorbeer G, Scharf S (2000) Regional aspects and statistical characterisation of the load with semivolatile organic compounds at remote Austrian forest sites. Chemosphere 40:1159-1171. doi:10.1016/S0045-6535(99)00365-3

Wu WZ, Schramm KW, Henkelmann B, Xu Y, Yediler A, Kettrup A (1997) PCDD/Fs, PCBs, HCHs and HCB in sediments and soils of Ya-Er Lake area in China: results on residual levels and correlation to the organic carbon and the particle size. Chemosphere 34: 191-202. doi:10.1016/S0045-6535(96)00351-7 